\title{
Establishing a simulation center for surgical skills
}

\author{
Angelo Maura · Gabriele Galatà · Francesco Rulli
}

Received: 18 July 2007/ Accepted: 14 August 2007/Published online: 11 December 2007

(C) Springer Science+Business Media, LLC 2007

Keywords Costs · Imaging · Virtual reality ·

Instruments $\cdot$ Training courses

We read with interest the article by Haluck et al. [1] which reported on how to establish a simulator center for surgical skills. The authors emphasized the importance of developing curricula that include virtual simulation. They analyze the costs and reliability of such laboratories. Moreover, they include as a target surgical patients and we do not really understand why. Then, unfortunately, the authors do not deal with the natural interface of a minimally invasive surgery (MIS) surgeon: the medical or biomedical engineer. We would like to suggest that medical engineers may be a useful target. Medical engineers need to be involved in simulation centers for surgical skills as well as in clinical MIS. Their involvement is important in better understanding the capabilities and ergonomics of a given surgical device. Medical engineers must be involved in the enhancement of existing instrumentation, conception of new and smarter devices, discussion of risk assessment, and eventually collaboratation in the development of new ideas. Finally, in their discussion, Haluck et al. conceive of the establishment of a training center with virtual reality

\footnotetext{
A. Maura $(\varangle) \cdot$ F. Rulli

Innovative Surgical Technologies, Faculty of Medical

Engineering, University of Rome, "Tor Vergata", Rome, Italy

e-mail: angelo.maura@tin.it

G. Galatà · F. Rulli

Department of Surgery, University of Rome, "Tor Vergata"

Viale Oxford 81, 00133 Rome, Italy
}

(VR) simulators. In our experience [2], VR simulators are expensive and their contribution to knowledge of new surgical devices is poor. On the other hand, box trainers allow for a better understanding of ultrasound, radiofrequency, surgical instrumentation, and so on.

We recently decided to test 11 medical engineering students in order to analyze and improve their practical and theoretical knowledge about MIS instrumentation while performing standardized MIS tasks on a pelvic trainer. The courses were held at the "Tor Vergata" University of Rome in a laboratory setting. The 11 medical engineering students had no experience in laparoscopy. Training included 3-h hands-on sessions over a three-month course. During the course the students attended theoretical and practical courses. The course validity was demonstrated by measuring significant improvement in performance with increasing skill. In conclusion, we showed that dry lab experience for medical engineering students is useful for teaching and improving analysis and management of laparoscopic devices, allowing identification of problems with the aim of developing better devices [3, 4].

\section{References}

1. Haluck RS, Satava RM, Fried G, Lake C, Ritter EM, Sachdeva AK, Seymour NE, Terry ML, Wilks D (2007) Establishing a simulation center for surgical skills: what to do and how to do it. Surg Endosc 21:1223-1232

2. Petrin P, Baggio E, Spisni R, Rulli F (2006) Use of virtual reality simulator in the training of postgraduated surgical residents. Ann Ital Chir 77(6):465-468

3. Rulli F (2007) Emotional evaluation and skill acquisition for proficiency-based laparoscopic skills training. Surgery 141(5):692

4. Rulli F, Cina G, Galatà G, Cina A, Vincenzoni C, Fiorentino A, Farinon AM (2004) Teaching subfascial perforator veins surgery: survey on a 2-day hands-on course. ANZ J Surg 74(12):1116-1119 